\title{
GLYCOALKALOIDS AFFECT PIGMENTS CONTENT OF SOME FRESH WATER ALGAE
}

\author{
Sanaa M. M. Shanab \\ Botany Dept., Faculty of Science- Cairo University, Giza- Egypt
}

\begin{abstract}
Chlorophyll a synthesis in unicellular green, unicellular and colonial blue-green algae was stimulated by moderate concentrations of both alkaloids used (solasodine and diosgenin). Chlorophyll b as well as carotenoids production was enhanced by lower concentrations of solasodine than diosgenin.

Phycobilins (phycocyanin and phycoerythrin) pigment production stimulated by lower solasodine and moderate diosgenin concentrations ( 0.004 and $0.02 \%$, respectively).

The investigated autotrophic green and blue-green algae are more susceptible to solasodine than to its oxygen isomer diosgenin alkaloid.
\end{abstract}

Key words: blue green algae, diosgenin, glycoalkaloids, green algae, pigments, Solanum sp., solasodine.

\section{Introduction}

The relation between glycoalkaloid levels and chlorophyll was discussed in a series of works. Liljemark and widoff, 1960; Ramaswamy et al., 1976; Ramaswamy and Nair, 1984; Herbreteau-Lemonnier et al., 1989; Dale et al., 1993 and Dao and Freidman, 1994 reported that there was a positive correlation between the increase in glycoalkaloids and the greening of potato tubers caused by chlorophyll production. The chlorophyll synthesis always preceded the synthesis of the glycoalkaloid, and the authers postulated that chloroplasts were responsible for the inconporation of labeled $\mathrm{CO}_{2}$ fixation into solasodine structure.

On the other hand, Gull and Isenberg, 1960; Jadhav and Salunkhe, 1975 concluded that no correlation between chlorophyll and glycoalkaloid synthesis and mentioned that they are two separated events; each event was dependent on different wavelengths of light (Jeppsen et al., 1974; Haard, 1977; Petermann and Morris, 1985; Rosenfeld et al., 1995).

Shanab (2000), studied the Solanum elaeagnifolium cultivated on solid media which were supplemented with different concentrations of cyanobacterial crude extracts of various blue-green algal species that include nitrogen-fixing, non-nitrogen fixing and toxin producing species. The obtained results demonstrated a stimulation of glycoalkaloid production (Solasodine and Diosgenin) by the extract of seven species out of ten experimented in this study.

This work was carried out to investigate the presence or not of a reversal correlation i.e. the application of glycoalkaloidal concentrations to unicellular and colonial algal cultures (green and blue-green) and to study their effects on algal growth and on different pigments synthesis. 


\section{Materials And Methods}

1. Alkaloids concentrations: Stock solutions of solasodine $(0.02 \mathrm{mg} / \mathrm{ml})$ and diosgenin $(0.2 \mathrm{mg} / \mathrm{ml})$ figure (1) from which the following alkaloid concentrations were prepared: $0.00,0.004,0.008,0.012,0.016,0.02,0.04,0.06,0.08$ and $0.1 \%$.
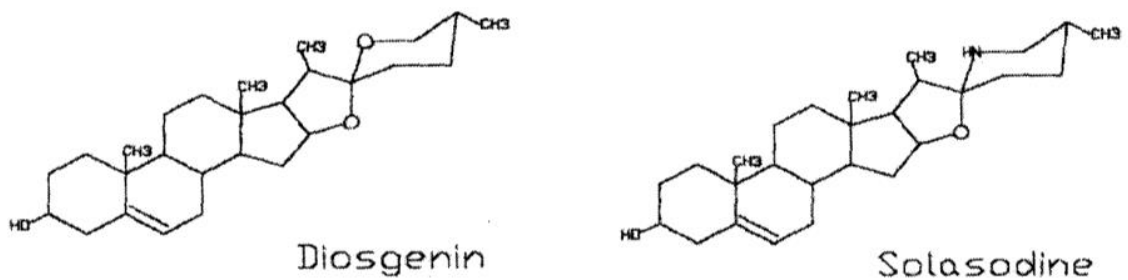

Fig. (1): Chemical structures of Solasodine $\&$ Diosgenin

2. Algal cultures: The algal species used in this study Ankistrodesmus acicularis, Scenedesmus obliquus (green algae); Microcystis aeruginosa, Aphanothece caldariorum (blue green algae) were previously isolated from Ain Helwan soil and hot spring, grown on solid Bold's nutritive medium then several subculturing were conducted on the solid and liquid media until isolation of unialgal species were performed.

Purification of algal cultures using a mixture of antibiotics was carried out according to Stein (1973). In $250 \mathrm{ml}$ conical flasks, add $5 \mathrm{ml}$ of 10 days-old algal suspensions, then the different alkaloid concentrations and complete to $50 \mathrm{ml}$ by Bold's liquid nutritive algal medium. Cultures were subjected to continuous illumination by cool white fluorescent lamps of an irradiant of $10 \mu \mathrm{mol} / \mathrm{m}^{2} / \mathrm{s}$ and incubated at $25^{\circ} \mathrm{C} \pm 1$ for 10 days.

\section{Pigment extraction and estimation:}

Extraction of chlorophyll a,b and carotenoid pigments: The algal suspension was centrifuged at $5000 \mathrm{rpm}$ for $15 \mathrm{~min}$. then $5 \mathrm{ml}$ of algal pellets were extracted using $90 \%$ acetone and kept over night in refrigerator at $4^{\circ} \mathrm{C}$. Using Spectrophotometric methods, absorbance at $663,644,633,452$ were recorded for the estimation of chlorophyll a,b and carotenoid contents according to (Metzner et al. 1965) and substitution in the following equations:

$$
\begin{gathered}
\mathrm{Chl} \mathrm{a}(\mathrm{ug} / \mathrm{ml})=10.3 \mathrm{~A} 663-0.918 \mathrm{~A} 644 \\
\mathrm{Chl} \mathrm{b}(\mathrm{ug} / \mathrm{ml})=19.9 \mathrm{~A} 644-3.87 \mathrm{~A} 633 \\
\text { Carotenoids }(\mathrm{ug} / \mathrm{ml})=4.2 \mathrm{~A} 452-(0.0246 \mathrm{Chl} \mathrm{a}+0.426 \mathrm{Chl} \mathrm{b})
\end{gathered}
$$

Extraction and estimation of phycobilins pigment: It was carried out according to O'Carra and Oh'Eocha (1976). Spectrophotometrically, the absorbance at wavelengths 663 and 550 was recorded and calculation of phycocyanin \& phycoerythrin pigments of blue-green algae was estimated according to the following equations:

Phycocyanin $=A 550 \times 15.15 \times$ total volume of extract*/taken volume $\times 1 / 1000$

Phycoerythrin $=\mathrm{A} 663 \times 12.4 \times$ total volume of extract/taken volume ${ }^{* *} \times 1 / 1000$

Phycobilins content $(\mathrm{mg} / \mathrm{g}$ fresh $\mathrm{wt})=$ Phycocyanin + Phycoerythrin

* total volume of extract $=$ algal suspension after centrifugation + volume of acetone

** taken volume $=$ algal suspension inoculum + algal nutritive medium + alkaloid conc . 


\section{Results}

L. Effect of different steroidal alkaloid (Solasodine) concentrations

* On unicellular green algae [Ankistrodesmus acicularis (Ank.), Scenedesmus aliquus (Scn.)]: Figure (2) illustrate that chlorophyll a content in Ankistrodesmus acicularis and Scenedesmus obliquus was stimulated by slightly higher solasodine concentrations with a maximum production at $0.02-0.06 \%$. Chlorophyll $\mathrm{b}$ and carotenoids content stimulated by very low solasodine concentrations $(0.004-0.008 \%)$ and the enhancement effect slightly decreased with increasing solasodine concentration till it reached constant level comparable to that of control $(0.012-0.08 \%)$. Higher solasodine concentrations inhibited pigment synthesis especially carotenoids which seemed to be more sensitive than chlorophylls to higher alkaloid concentrations.
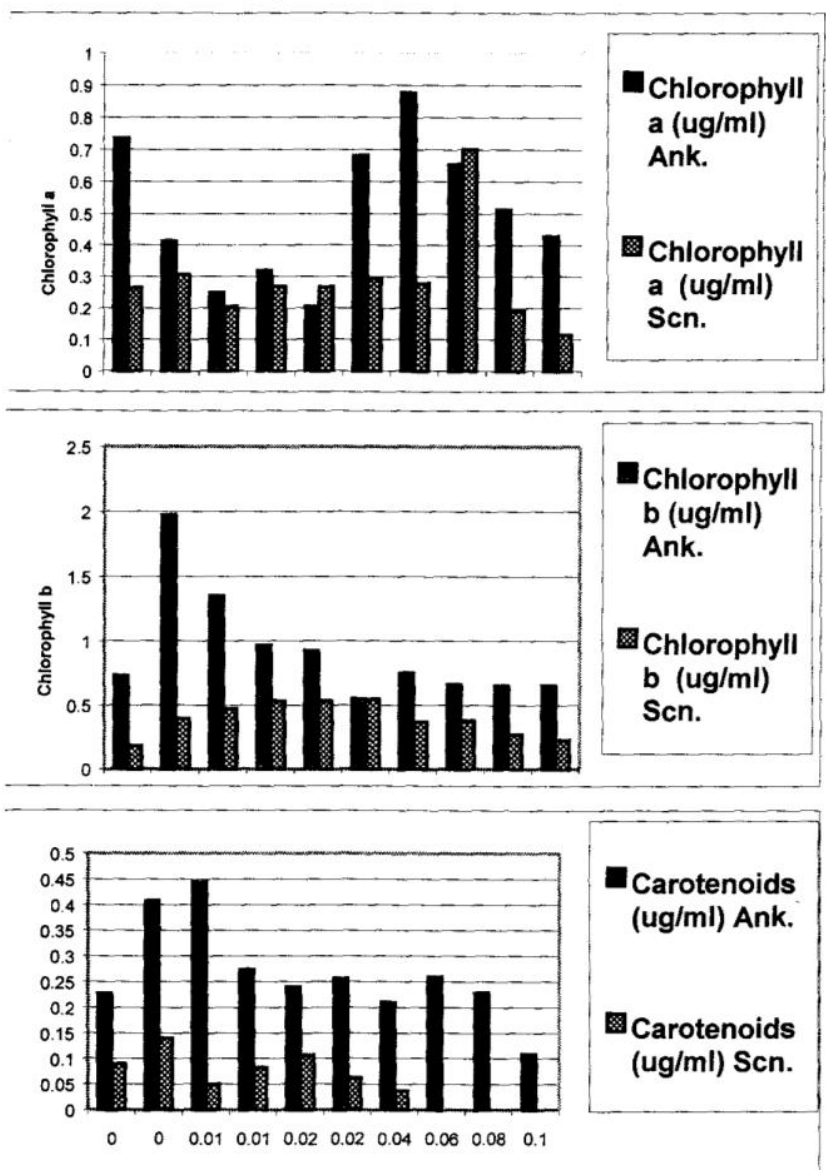

TE. (2): Effect of solasodine treatment on chlorophyll a,b and carotenoid contents' in both Ankistrodesmus and Scenedesmus.

Esapt. J. Phycol. 1, 2000. 
* On blue-green algae [Microcystis aeruginosa (Mic.), Aphanothece caldariorum (Aph.)]. Figure (3) demonstrated that synthesis of chlorophyll a and carotenoids were stimulated by lower solasodine concentrations $(0.004-0.016 \%)$, which recorded maximum productions of the chlorophyll a and carotenoids. Figure (4) demonstrated phycobilin (phycocyanin and phycoerythrin) production, which was enhanced by lower solasodine concentration (maximum at $0.004 \%$ ). Beyond this level, it registered a gradual decrease with increasing concentrations till it gave a comparable phycobilin contents to that of control at higher alkaloid concentrations.
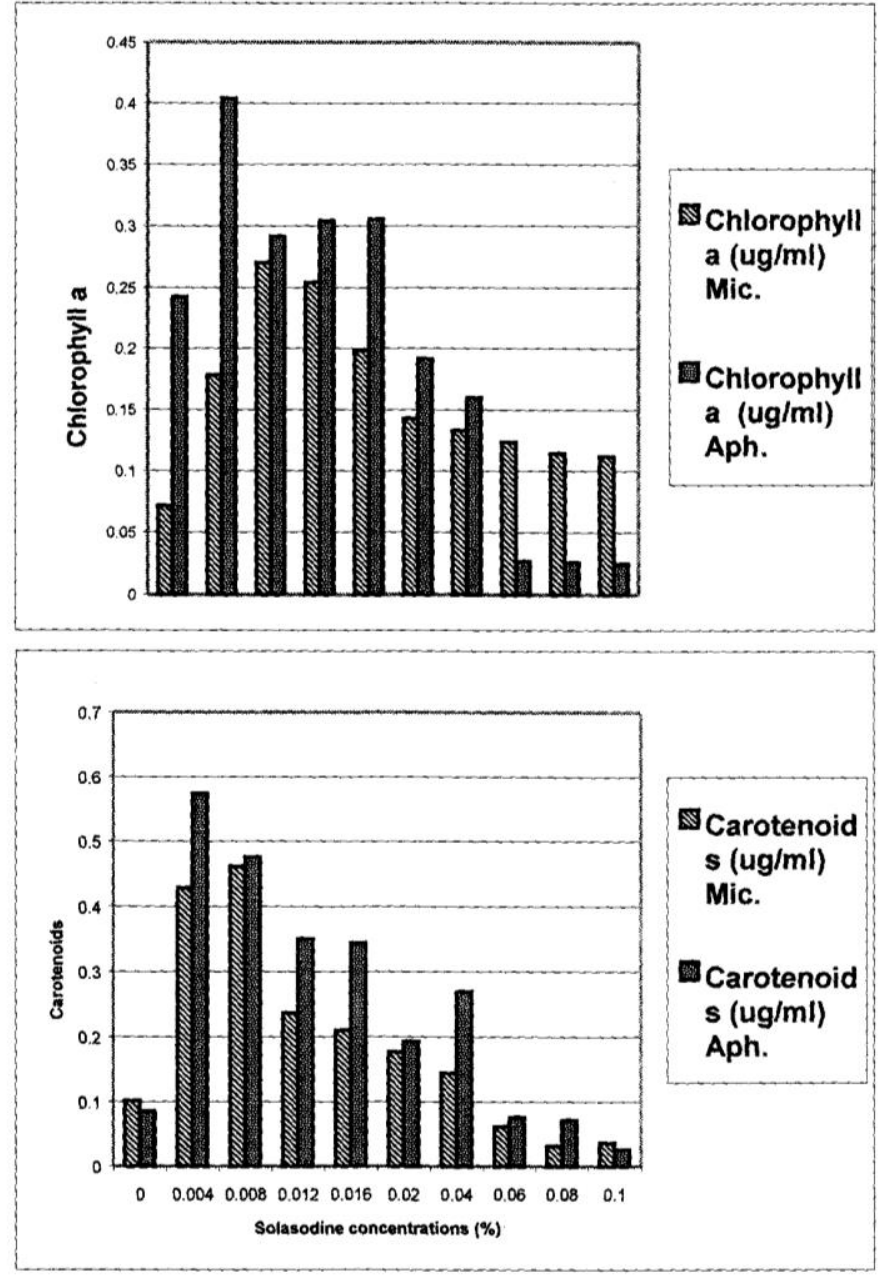

Fig. (3): Effect of Solasodine treatment on Chlorophyll a and Carotenoid contents' in both Microcystis and Aphanothece. 


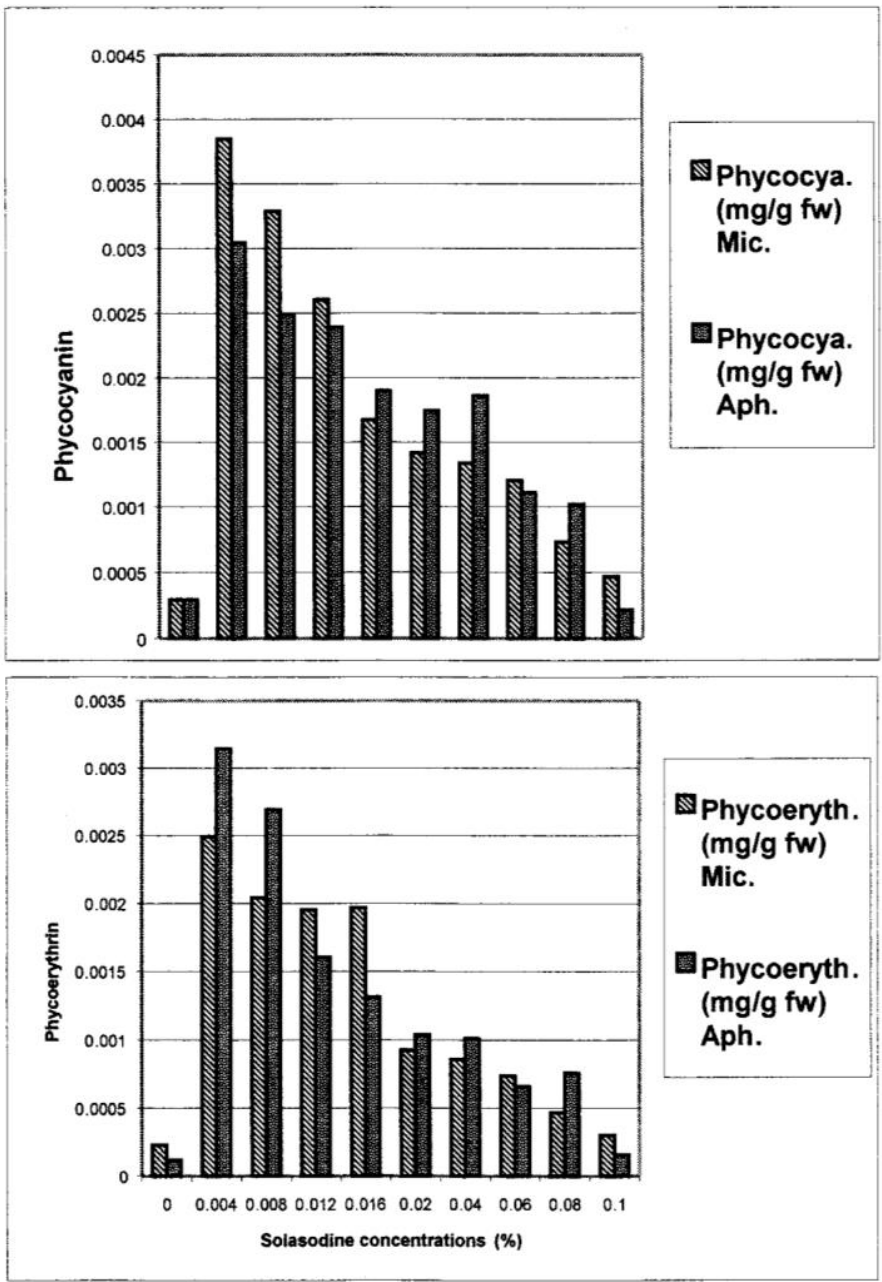

Fig. (4): Effect of Solasodine treatment on Phycobilins content in both Microcystis aeruginosa\& Aphanothece caldariorum

\section{Effect of different steroidal sapogenin (Diosgenin) concentrations}

* On unicellular green algae (Ankistrodesmus acicularis, Scenedesmus obliquus): Figure (5) represented the stimulation of chlorophyll a and carotenoids with increasing diosgenin concentrations till it reached the maximum pigments synthesis at $0.02 \%$ of alkaloid supply, then the pigment contents decreased sharply with increasing concentrations. It seemed that carotenoid production was more sensitive to higher alkaloid concentrations than that of chlorophyll a. 
Chlorophyll $\mathrm{b}$ production was gradually enhanced by increasing diosgenin concentrations and its content reached maximal at $0.02-0.08 \%$ of the alkaloid concentrations especially in case of Ankistrodesmus acicularis, while in case of Scenedesmus obliquus, maximum production was at $0.06 \%$ of the alkaloid. At increased concentrations, chlorophyll b content slightly decreased but still exceeded that of control.

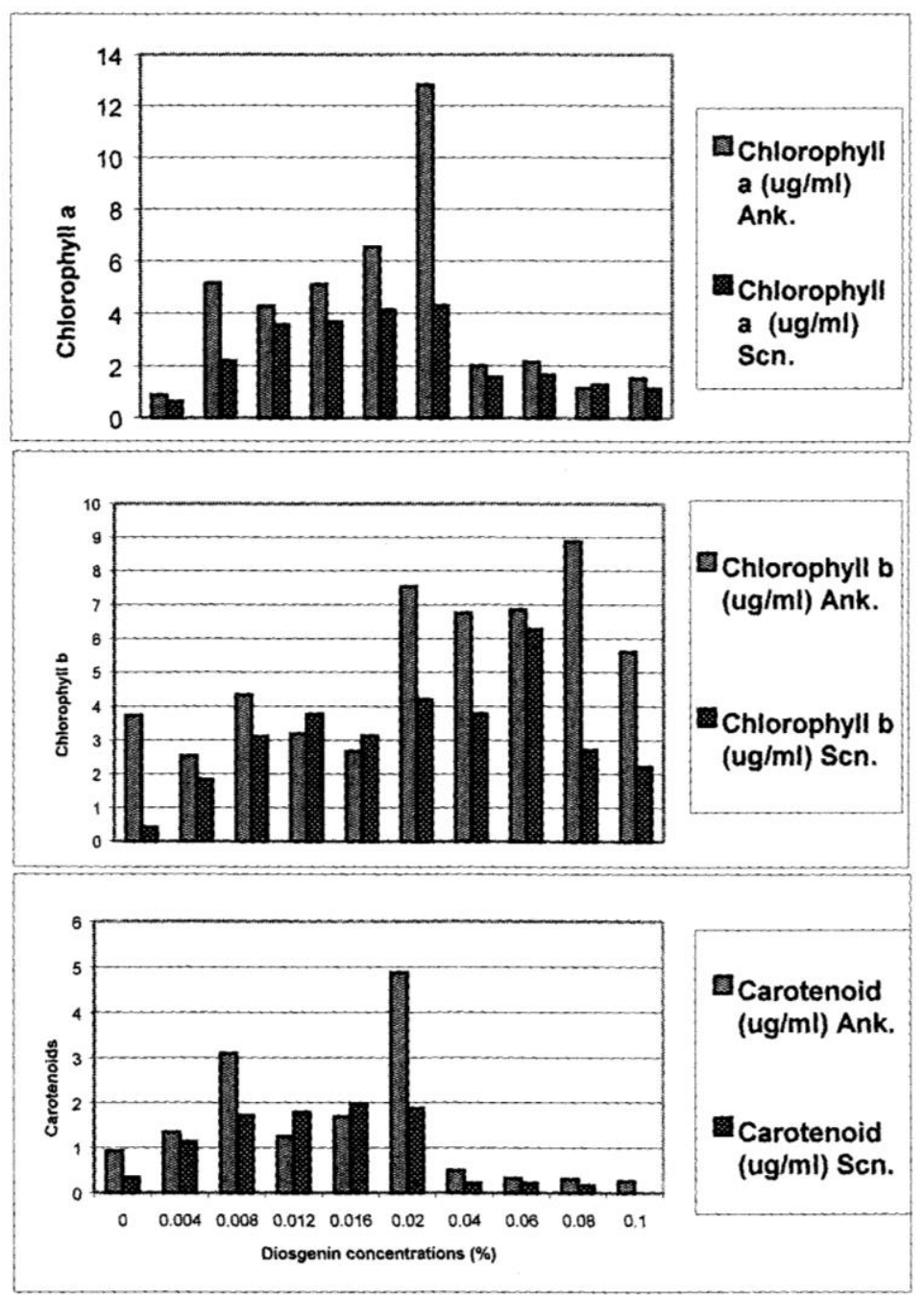

Fig. (5): Effect of Diosgenin treatment on Chlorophyll a, b and carotenoid contents' in both Ankistrodesmus acicularis\& Scenedesmus obliquus. 
* On blue-green algae (Microcystis aeruginosa, Aphanothece caldariorum): Figure (6) demonstrated that chlorophyll a synthesis seemed to be enhanced by moderate concentrations of $0.004-0.02 \%$ in case of Microcystis aeruginos $a$ and of $0.012-0.02 \%$ in Aphanothece caldariorum.

Carotenoids synthesis stimulated by elevating diosgenin concentrations till it reached maximum content at $0.04 \%$ in case of Microcystis aeruginosa (11-folds that of control) and it sharply decreased with increasing diosgenin concentrations and reached complete inhibition at $0.1 \%$. In case of Aphanothece caldariorum, the effect went parallel to that of Microcystis aeruginosa without reaching a maximum production at specific diosgenin concentrations.
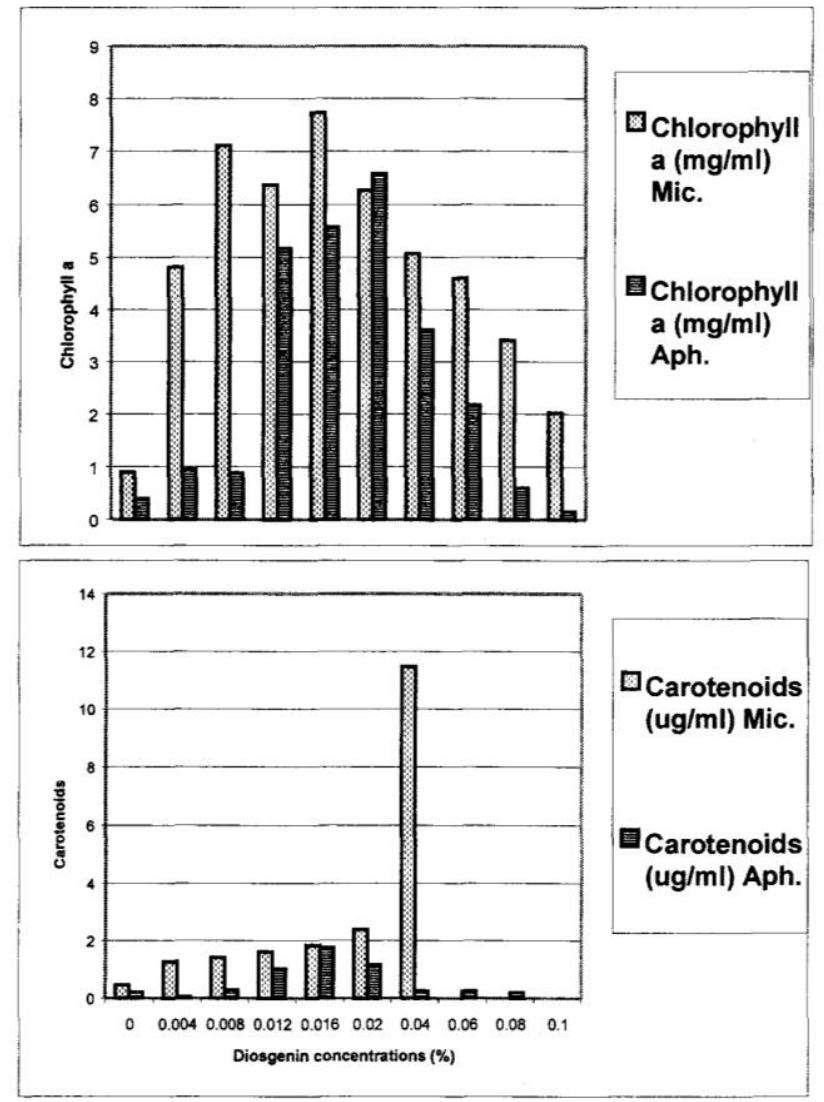

Fig. (6): Effect of Diosgenin treatment on Chlorophyll a and carotenoid contents' in both Microcystis aeruginosa \& Aphanothece caldarioeum. 
Phycobilin (phycocyanin and phycoerythrin) synthesis was illustrated in figure (7) where a gradual stimulation was recorded with increasing the steroidal sapogenin concentrations. Phycocyanin reached its maximum production at $0.02 \%$ in case of Microcystis aeruginosa and at $0.016 \%$ in case of Aphanothece caldariorum. Further increase in concentration resulted in conspicuous decrease in the pigment contents but its value remain higher than that of the control. Phycoerythrin gave comparable results to those of phycocyanin in case of Microcystis aeruginosa while in Aphanothece caldariorum culture the stimulatory effect of phycoerythrin synthesis was remarkably enhanced by higher concentrations of diosgenin (0.04-0.1\%).

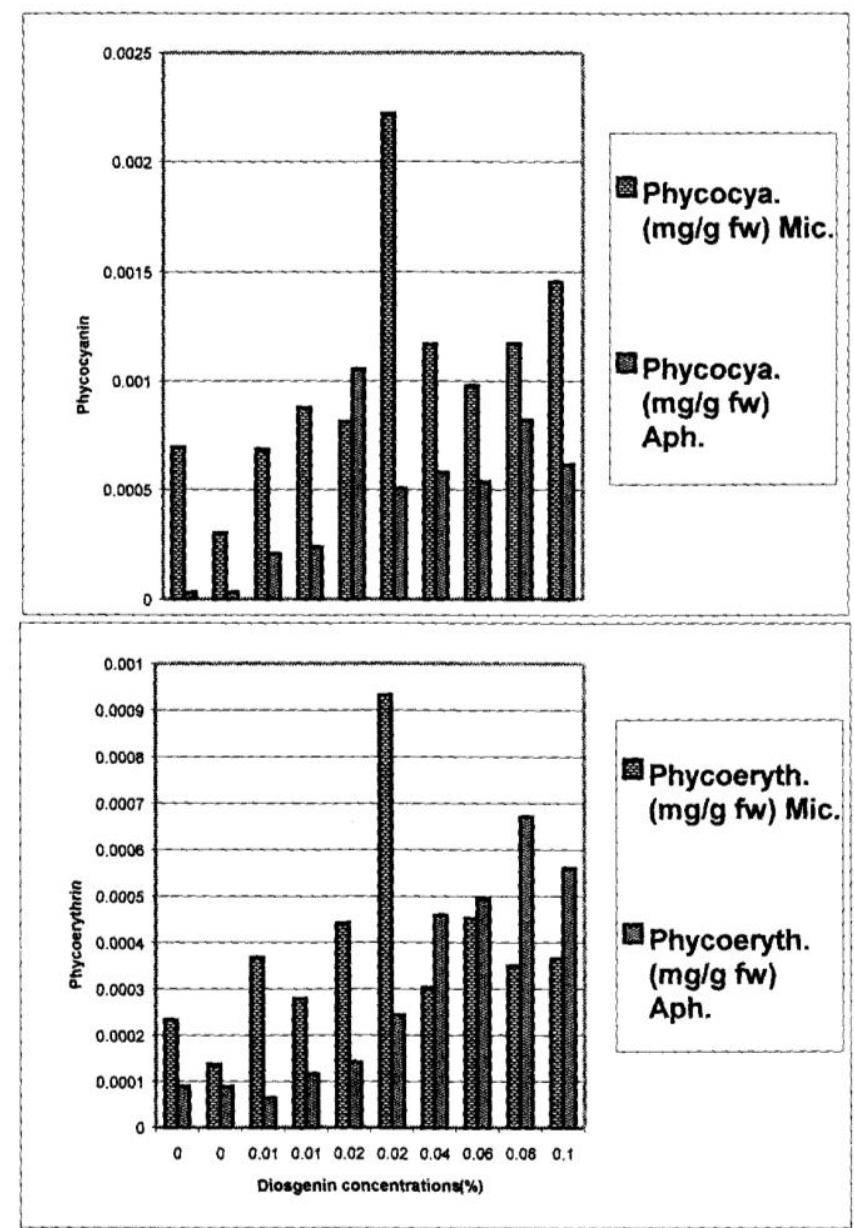

Fig. (7): Effect of Diosgenin treatment on Phycobilins content in both Microcystis aeruginosa and Aphanothece caldariorum. 
It recorded a gradual bleaching of algal culture especially in case of blue green algae at higher alkaloid concentrations $(0.02-0.1 \%)$. This event was associated with turbidity and unpleasant odor.

\section{Discussion}

The correlation between glycoalkaloids and pigments were mostly carried out on various Solanum species. Conner, 1987 concluded that solasodine biosynthesis in leaves of Solanum laciniatum tissue culture grew autotrophicaly or heterotrophicaly was greatly promoted or dependent upon the actively photosynthesizing chloroplasts and its content approached to that of the field grown plants.

Herbreteau-Lemonnier et al., 1989 reported somaclonal variation in solasodine content (in fruits and leaves) and pigment contents (only in leaves) of 11 plants derived from callus tissue culture explants of $S$. laciniatum. They recorded the high content of the glycoalkaloid in fruits of all the tested plants and the positive correlation between solasodine and total chlorophyll content in leaves. These results confirmed the previous findings of Kuznetsova et al., 1978 for S. laciniatum leaves and of Ramaswamy et al.,1976; Ramaswamy and Nair, 1984; Petermann and Morris,1985 and Dao and Freidman, 1994 for greening potato tubers.

Fábregas et al.,(1996; 1997 and 1998) used 5 soluble fractions of potato homogenate (germinated or not) to semicontinuous mixotrophic cultures of the marine microalgae Phaeodactylum tricornutum and Tetraselmis suecica. The authers reported that the photoheterotrophic cultures enhanced the production of much more chlorophyll and carotenoids than the autotrophic control. They also suggested the feasibility of the use of potato extracts (as a cheap substrate) for the cost effective production of microalgal biomass and pigments.

Dao and Friedman (1994) reported increased glycoalkaloid (300\%), chlorophyll and chlorogenic acid concentrations after exposing potato to fluorescent light for 20 days. The usual indication that a potato may have increased glycoalkaloid levels due to light exposure is greening (chlorophyll productions).

In a series of related papers (Ramaswamy et al., 1976; Nair et al., 1981; Ramaswamy and Nair, 1984), chlorophyll synthesis always preceded the synthesis of glycoalkaloids in cold-stored potatoed and the formation of both appeared to be related. The authers postulated that chloroplasts were responsible for the incorporation of labeled $\mathrm{CO}_{2}$ fixation into solanidine structure. Spoladore et al., 1983 found a correlation between glycoalkaloids and greening intensity. Liljemark and Widoff, 1960 and Dale et al., 1993 also reported that there was a connection between the two-biochemical events.

On the other hand, Gull and Isenberg, 1960 found no correlation between chlorophyll and glycoalkaloid synthesis. Patil et al., 1971subjected 11 varieties of potato to various light intensities caused a significant effect on chlorophyll production without similar changes in glycoalkaloid levels. Jadhav and Salunkhe, 1975 concluded that chlorophyll and glycoalkaloid synthesis were two separated events and if chlorophyll and glycoalkaloid biosynthesis are linked, why does mechanical injury produce large increases of glycoalkaloids even in the dark with no evidence of higher chlorophyll production?

Fábregas et al., (1996; 1997 and 1998) analyzed the potato soluble fractions and referred the photoheterotrophic enhancement in algal productivity and pigmentation to their contents of phosphate, nitrogen (as nitrate, nitrite, ammonium or free amino acids) 
organic carbon and free glucose comparing with photoautotrophic culture that include only inorganic nutrients. The authors didn't mention the glycoalkaloid contents in potato especially in the germinated tubers (sprouts contain the highest alkaloid content) and concluded that another factor seemed present in the extract which control the pigment production in the cells cultured in organic media.

Homogenation (similar to mechanical damage) of potato tubers for the preparation of soluble fractions (Fábregas et al., 1997 and 1998), considered stressful condition leading to increase in glycoalkaloid content and may be the production of phytoalexins and phenolics. These substances might have an enhancement effect on pigment synthesis.

Shanab, 2000 studied the effect of cyanobacterial crude extracts on solasodine and diosgenin production. This investigation demonstrated that at least five of ten cyanobacterial species used manifested an enhancement of alkaloid synthesis in Solanum elaeagnifolium tissue cultures.

The obtained results in the present investigation demonstrated the stimulatory effect of lower solasodine concentrations and moderate to slightly higher diosgenin concentrations on the pigment synthesis either the photosynthetic or the accessory ones and the inhibitory effect of higher concentrations especially to carotenoid synthesis. These results demonstrated clearly that each algal pigment was differently affected by either alkaloid and that solasodine is more efficient in stimulating pigment synthesis than its oxygen isomer diosgenin.

Our results were in an inverse agreement with the previously reported positive correlation between glycoalkaloid and pigment contents (low glycoalkaloids concentrations stimulated higher pigment productions) either using tissue cultures of $S$. laciniatum (Kuznetsova et al., 1978; Herbreteau-Lemonnier et al., 1989) or greening of potato tubers (Petermann and Morris, 1985).

Mc Kee, 1959; Marrow and Caruso, 1983; Hazel, 1988; Griffin, 1994 and Hanna et al., 1996 recorded the antifungal and antibacterial properties of glycoalkaloids. They also mentioned that although most fungal and bacterial strains were inhibited by glycoalkaloids but some other strains of successful pathogen have developed a detoxifying mechanism so, became immune.

The results from this paper suggest the feasibility of the use of relatively low glycoalkaloid concentrations (can be extracted from Solanum sp.) for the effective production of algal pigments.

\section{References}

Conner, A. J. 1987 Differential solasodine accumulation in photoautotrophic and heterotrophic tissue cultures of Solanum laciniatum. Phytochemistry, 26(10): 2749-2750.

Dale M. F. B., Griffiths D. W., Bain H. and Todd D. 1993 Glycoalkaloid increase in Solanum tuberosum on exposure to light. Ann. Appl. Biol., 123: 411-418.

Dao L. and Friedman M. 1994 Chlorophyll, chlorogenic acid, glycoalkaloids and protease inhibitor content of fresh and green potatoes. J.Agric. Food Chem. 42:633-639. 
Fábregas J., Morales E., Polanco N., Patiño M. and Otero A. 1996 Soluble fractions of Solanum tuberosum enhance cell and pigment production of semi-continuous cultures of the microalga Phaeodactylum tricornutum. Letters in Applied Microbiology, 23:223-226.

Fábregas J., Morales E., García D., Cabezas B. and Otero A. 1997 the soluble fractions of Solanum tuberosum enhances growth and pigmentation of microalga Tetraselmis suecica under photoheterotrophic conditions. Bioresource Technology, 59:263-266.

Fábregas J., Morales E., Arán J. and Otero A. 1998 Germinated Solanum tuberosum : An agricultural product of marine microalgae culture. Bioresource Technology, 66:19-24.

Griffin D. H. 1994 Fungal physiology, Wiley-Liss, New York $\left(2^{\text {nd }}\right.$ ed $)$.

Gull D. D. and Isenberg F. H. 1960 Chlorophyll and solanine content and distribution in four varieties of potato tubers. Proc. Am. Soc. Hortic. Sci., 75:545-556.

Haard N. 1977 Glycoalkaloid content of Newfoundland grown potato tubers and potato wart tissue. J. Food Biochem., 1:57-65.

Hanna A. G., Yassin F. Y. S., Allam R. I., Yassin N. and EI Kassaby I. 1996 A phytochemical screening of some Solanaceous plants. Phytosterol and fatty acid constituents of Solanum elaeagnifolium and Solanum nigrum in addition to preliminary pharmacological and antimicrobial investigation. Egyptian J. Pharm. Sci.,37(1): 211-231.

Hazel W. J., Bean G.A. and Goth R.W. 1988 Relationship of potato leaf sterols to development of potato late blight caused by Phytophthora infestans on U.S. potato clones and breeding lines. Plant disease 72(3): 203-205

Herbreteau-Lemonnier C., Rossignol L., Rossignol M., Sihachakr D. and Haicour R. 1989 Solasodine and pigment contents of plants derived from callus culture of Solanum laciniatum Ait. Phytomorphology, 39(1): 93-96.

Jadhav S. J. and Salunkhe D. K. 1975 Formation and control of chlorophyll and glycoalkaloids in tubers of Solanum tuberosum L. and evaluation of glycoalkaloid toxicity. Adv. Food Res., 21:307-354.

Jeppsen R. B., Wu M. T. and Salunkhe D. K. 1974 Some observations on the occurrence of chlorophyll and solanine in potato tubers and their control by N6benzyladenine, ethephon and filtered lights. J. Food Sci., 39:1059-1061.

Liljemark A. and Widoff E. 1960 Greening and solanine development of white potato in florescent light. Am. Potato J., 37:379-388.

Mc Kee R. 1959 Factors affecting the toxicity of solanine and related alkaloids to Fusarium caeruleum. J. Gen. Microbiol. 20: 686-696.

Metzner H., Rau H. and Senger H. 1965 Untersuchungen zür synchonisierbarteit einzelner Pigmentan Angel Mutanten von Chlorella. Planta 65:186-190.

Morrow L. S. and Caruso F. L. 1983 Effect of potato seed tuber glycoalkaloid content on subsequent infection by Rhizoctonia solani. Am. Potato J. 60: 403-407.

O'Carra P. and O'h-Eocha C. 1976 Algal biliproteins and phycobilins. In: (Ed. T.W.Goodwin), chemistry and biochemistry of plant pigments. Vol.1, pp.328376, Academic press, London, New York -San Francisco.

Patil B. C., Salunkhe D. K. and Singh B. 1971 Metabolism of solanine and chlorophyll in potato tubers as affected by light and specific chemicals. J. Food Sci., 36:474476.

Egypt. J. Phycol. 1, 2000. 
Petermann J. B. and Morris S. C. 1985 the spectral responses of chlorophyll and glycoalkaloid synthesis in potato tubers (Solanum tuberosum). Plant Sci., 39:105-110.

Ramaswamy, N. K.; Behere, A. G. and Nair, P. M. 1976 A novel pathway for the synthesis of solanidine in the isolated chloroplast from greening potatoes. Eur. J. Biochem., 67:275-282.

Ramaswamy, N. K. and Nair, P. M. 1984 Evidence for the operation of C1-pathway for the fixation of $\mathrm{CO} 2$ in isolated intact chloroplasts from green potato tubers. Plant Sci. Lett., 34:261-267.

Rosenfeld H. J., Sundell H. A., Lea P. and Ringstad M. 1995 Influence of packaging materials and temperature on the glycoalkaloid content of potato tubers. Food Res. Int., 28:481-484.

Shanab S. M. 2000. Effect of fresh water Cyanobacterial extracts on glycoalkaloid production of the in vitro Solanum elaeagnifolium tissue culture. Arab J. Biotechn. (in press)

Spoladore D. S., Teixeira J. P. F., Zullo M. A. T., Teixeira P. R. M., Cohelo S. M. R. and Miaranda, Filho H. S. 1983 the occurrence of glycoalkaloids and greening in recently harvested and stored potato tubers. Brigantia, 42:221-231.

Stein J. R. 1973 Hand book of Phycological methods: culture methods and growth measurements. Cambridge University press, pp.448.

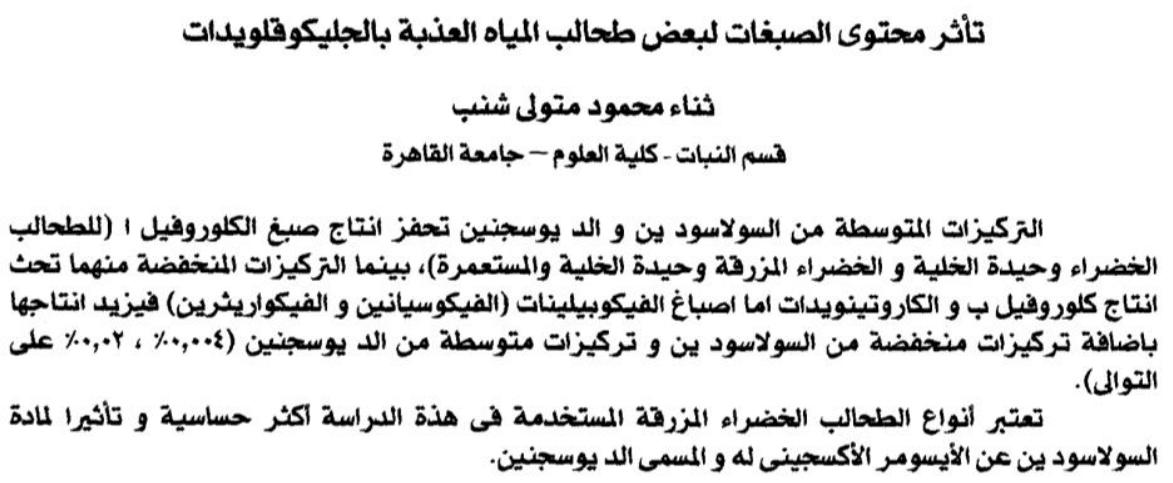

